\title{
Spring Flood Forecasting Based on the WRF-TSRM Mode
}

\author{
Xianyong MENG, Zhiqun SUN, Honggang ZHAO, Xiaonan JI, Hao WANG, Lianqing XUE, Hongjing WU, Yongnan ZHU
}

\begin{abstract}
The snowmelt process is becoming more complex in the context of global warming, and the current existing studies are not effective in using the short-term prediction model to drive the distributed hydrological model to predict snowmelt floods. In this study, we selected the Juntanghu Watershed in Hutubi County of China on the north slope of the Tianshan Mountains as the study area with which to verify the snowmelt flood prediction accuracy of the coupling model. The weather research and forecasting (WRF) model was used to drive a double-layer distributed snowmelt runoff model called the Tianshan Snowmelt Runoff Model (TSRM), which is based on multi-year field snowmelt observations. Moreover, the data from NASA's moderate resolution imaging spectroradiometer (MODIS) was employed to validate the snow water equivalent during the snow-melting period. Results show that, based on the analysis of the flow lines in 2009 and 2010, the WRF-driven TSRM has an overall $80 \%$ of qualification ratios (QRs), with determination coefficients of 0.85 and 0.82 for the two years, respectively, which demonstrates the high accuracy of the model. However, due to the influence of the ablation of frozen soils, the forecasted flood peak is overestimated. This problem can be solved by an improvement to the modeled frozen soil layers. The conclusion reached in this study suggests that the WRF-driven TSRM can be used to forecast short-term snowmelt floods on the north slope of the Tianshan Mountains, which can effectively improve the local capacity for the forecasting and early warning of snowmelt floods.
\end{abstract}

Keywords: early warning; MODIS; snowmelt model; TSRM; WRF

\section{INTRODUCTION}

Flooding is one of the most frequent and devastating natural disasters in the World, which has threatened the survival and development of China for thousands of years. Over the past 50 years, China has made great strides towards water conservancy, flood control, and disaster mitigation. However, due to the abnormal variation of the climate and the impact of large-scale human activities on the environment, flooding in China remains a very serious problem and flood-related events can still occur. China has the most snow in countries located at the middle and low latitudes, with the amount of winter snow equivalent to $740 \times 10^{8} \mathrm{~m}^{3}$ of water. The arid areas in northwest China are extremely short of surface water resources, as they cover about $25 \%$ of China's land area while only having $3.3 \%$ of the surface water. However, they are the most snow-rich areas, with a large amount of seasonal snow. Among the three main snow areas in China, two-fifths are concentrated in northwest China. In these areas, alpine seasonal snow is one of the main sources of rivers, and plays an extremely important role in the rational use of water resources.

Numerous studies show that the snow in Xinjiang is more unique, accounting for about one-third of the snow water resource in China [1-2]. Furthermore, 50 to $80 \%$ of the river runoff in Xinjiang is from seasonal snow. There is a very close relationship between seasonal snow and the productivity of both agriculture and animal husbandry in Xinjiang. A thick snow covering not only can lead to wheat being free from frost damage, but can also provide favorable conditions for spring agricultural water. However, when a thick snow covering is followed by continuous warm weather or rain in the Spring, fast snow melting will lead to Spring floods in some areas, which might destroy farmland, hinder traffic, and threaten people's lives and property. An effective way to solve problems related to the ecological hydrology and environment in the water basin is by simulating and forecasting the process of snowmelt flood formation using a distributed hydrological model [3-5]. Furthermore, one of the most effective ways to predict the snowmelt runoff is to establish a distributed snowmelt runoff model [7-9]. Many studies have found that using a distributed snowmelt model to predict snowmelt runoff in real time is important, especially for the Tianshan Mountains. However, it has not been carried out effectively for the above-mentioned types of studies.

In order to specifically set up a snow warning platform for the northern slopes of the Tianshan Mountains, and meet the requirement to consider the proposed mesoscale prediction system based on a distributed driving snowmelt model, in this study we propose the use of the Weather Research and Forecasting (WRF) driven Tianshan Snowmelt Runoff Model (TSRM), which provides further validation of prediction precision.

\section{STATE OF THE ART}

Many scholars have developed hydrological models that can simulate the snowmelt process, such as the variable infiltration capacity (VIC) and soil and water assessment tool (SWAT), but these models do not provide effective solutions for problems related to snow melting, since they are unable to cope with such a large scale or suffer from a lack of local data. However, Pei et al. [10] proposed the creation of a distributed snowmelt runoff model using 3S (Remote Sensing-RS, Geographical information System-GIS and Global Positioning SystemGPS) technology in 2007. In addition to the fact that the structure of hydrological models need to be improved, the lack of meteorological observations in mountainous areas is a further limiting factor in accurately forecasting Spring snowmelt flooding. The scarcity of data from mountainous regions, the particularity of the hydrological processes, and the complexity of the related mechanisms increase the difficulty of studying various kinds of surface processes in mountainous areas during snow-melting periods. The atmosphere-hydrology coupled model can be used to resolve this problem, and its use for simulating and forecasting snowmelt floods has attracted a great deal of global research attention. The development of the atmosphere-hydrology coupled model can therefore help 
to improve the prediction accuracy of both the atmospheric and hydrological models, and can maximize the effective forecast period of snowmelt floods. For example, Kenneth et al. [11] coupled the fifth-generation Penn State/National Center for Atmospheric Research mesoscale model (MM5) and the distributed hydrology soil vegetation model (DHSVM), and carried out a snowmelt flood forecasting experiment in the Snoqualmie River Basin in western Washington, USA. They concluded that updating the weather forecast field in real time can effectively reduce the runoff output error. Furthermore, Evans et al. [12] coupled four regional climate models with the same hydrological model to predict the alpine snowmelt runoff in the Verzasca Valley in Switzerland, thereby providing an important scientific reference for an atmosphere-hydrology coupled model's performance on predicting snowmelt runoff in alpine-cold areas. Zhao et al. [13] used a WRF-driven DHSVM to predict the snowmelt runoff process of the Juntanghu Watershed on the north slope of the Tianshan Mountains for $24 \mathrm{~h}$ and obtained several interesting results. Finally, $\mathrm{Wu}$ et al. [14] combined WRF and Micromet dynamical and statistical downscaling to drive the snow-melting model and simulate the Spring snow-making process in the Kayiertesi Watershed, demonstrating that combining WRF and distributed hydrological models is an effective way to forecast high-resolution snowmelt floods in mountainous areas.

Although many studies have forecasted snowmelt floods in various alpine-cold areas, any research that has used WRF to drive a localized snowmelt runoff model based on field observations has not been conducted effectively. Based on field observations from the North Slope of the Tianshan Mountains, the study reported on in this study will establish a better localized forecasting system by utilizing a WRF-driven double-layer distributed snowmelt runoff model to predict the Spring snowmelt floods in this area. This will provide a production basis for, and better protection of, the "oasis economy" of Xinjiang $[15,16]$.

Water resources are scarce and valuable, and good water resource management can lead to their better development. However, due to its complexity and uncertainty, improving water resource management has become a challenge, particularly in arid and cold areas. Hydrological models are very important due to their great significance in better utilizing current hydrological theories for improving or creating new management strategies. Although hydrological models have been widely used in regional water resource simulation, several difficulties are still manifested when they are applied in practical applications. For example, the simulation of ice and snow resources that are covered by alpine mountains is still problematic for simulating water resources globally.

Snowmelt models have yet to be built for many specific research areas (e.g., the north slope of the Tianshan Mountains). In addition, considering the larger topography of this area, the degree of temporal and spatial differentiation is extremely large. Therefore, we need to use the WRF model to provide accurate weather forecasts for the watershed, thus driving the snowmelt model, so that we can get more accurate snowmelt flood results. Owing to practical limitations, traditional mountain meteorological observation stations are very scarce in such areas, which makes it difficult to calibrate the snowmelt model using the data from traditional observation stations. The above limitations have prompted us to study the combined WRF-TSRM mode.

This rest of this study is organized as follows. In Section 3, the methodology and input data are described. In Section 4, the TSRM is forced by WRF, and several validating analyses are carried out, from which comparison of the numerical forecasts and the results of analysis are obtained. Conclusions are given in Section 5.

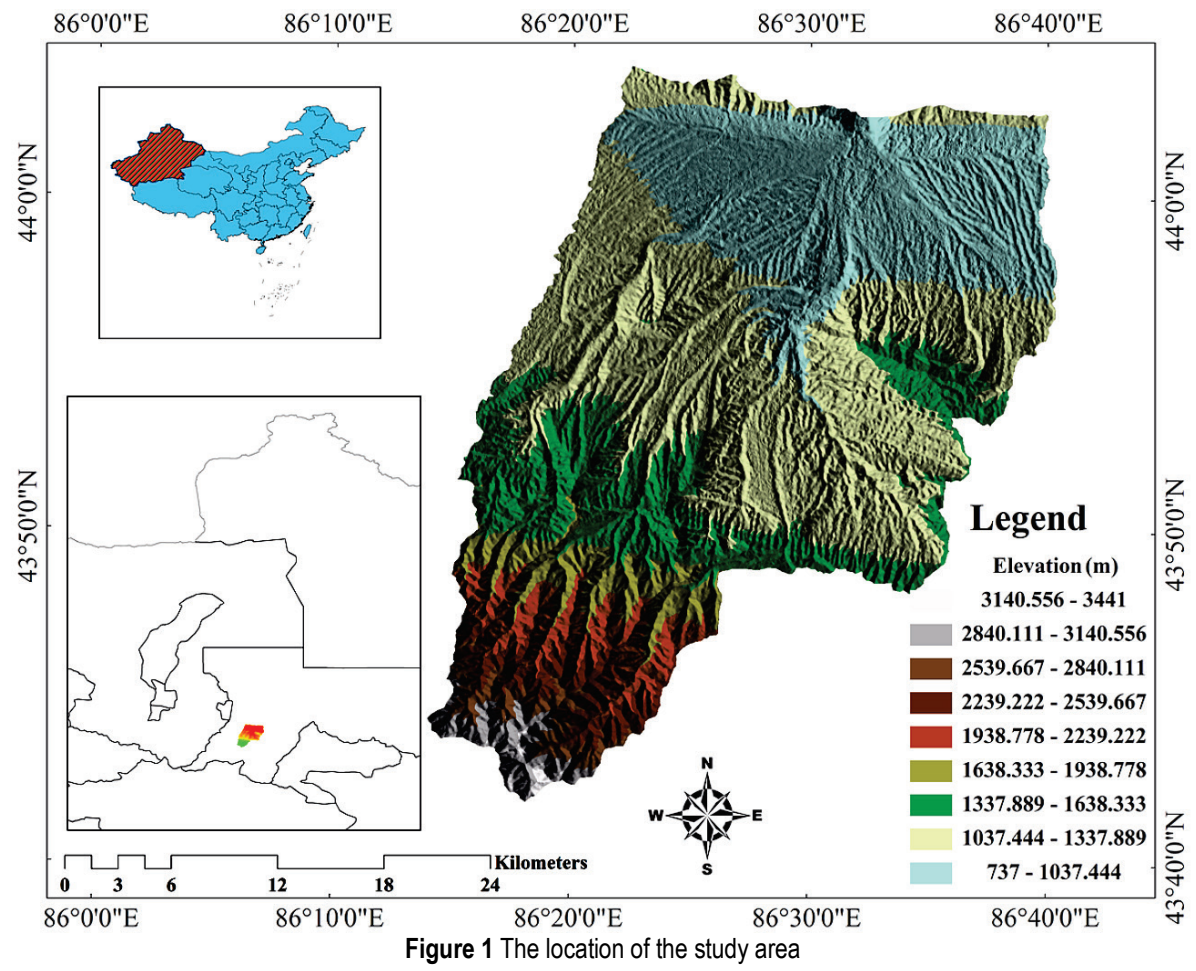




\section{METHODOLOGY}

\subsection{Study Area}

The study area $\left(43^{\circ} 43^{\prime} \mathrm{N}-44^{\circ} 06^{\prime} \mathrm{N}, 86^{\circ} 10^{\prime} \mathrm{E}-86^{\circ} 40^{\prime} \mathrm{E}\right)$ is the Juntanghu Watershed in the Hutubi County, Xinjiang. The meteorological observation stations are scarce in this area [17]. The Juntanghu River is a small river in the western part of the Tianshan Mountains, which originates from the north slope of the mountains. Through a statistical analysis using geographical information system (GIS) tools, the elevation of the river basin's source is about $3400 \mathrm{~m}$, and the elevation of most of the river basin is $1000-1500 \mathrm{~m}$. The river network converges in Nazha'er in the lower mountain, flows into the plain across the front-range hills in the western part of Hutubi County, and feeds into the Hongshan Reservoir at the mountain pass. The river is about $45.20 \mathrm{~km}$ long from its source to the Hongshan Reservoir. The catchment area above the Hongshan Reservoir is $833.57 \mathrm{~km}^{2}$, and the average elevation of the watershed is $1503 \mathrm{~m}$. The average slope is $62.5 \%$ above the confluence of the two main tributaries and $52.6 \%$ below it. The average annual runoff of the river is $3.89 \times 10^{8} \mathrm{~m}^{3}$. From mid-September, there is snow in the alpine area, the amount of which reaches its maximum level in January with the decrease of temperature. In February, the temperature begins to rise and the snow begins to melt, with the melting process speeding up in March. The runoff of the Juntanghu River is not uniformly distributed in different times of the year, and it reaches its maximum level in the spring. From March to June, the heavy rain in the watershed area and the snowmelt water combine and the flooding process is rapid, resulting in snowmelt floods occurring almost every year and causing significant harm to people's lives and property and to the ecological environment [1]. The area's watershed is fully developed and its features are typical. The study area is shown in Fig. 1.

\subsection{Tianshan Snowmelt Runoff Model (TSRM)}

The double-layer snowmelt model divides the snow cover into two layers according to the variations in energy and water (see Fig. 2). It can be approximated that when the snow depth $h$ exceeds $0.2 \mathrm{~m}$, the snow layer can be seen as two layers, whereas when the snow depth $h$ is less than $0.2 \mathrm{~m}$, the snow layer can be seen as one single layer. The upper snow layer absorbs energy through the input of factors, such as precipitation, turbulence, and solar shortwave radiation, and the energy of the lower layer comes mainly from the soil flux.

When considering the double snow layers, the energy balance of the upper snow layer can be calculated as

$Q_{n e t}=Q_{s n}+Q_{\mathrm{ln}}+Q_{p}+Q_{s}+Q_{l e}+Q_{c}$,

where $Q_{n e t}$ is the net energy flux going into the upper layer per unit time, $Q_{l n}$ the net longwave radiation flux, $Q_{s n}$ the net shortwave radiation flux, $Q_{p}$ the heat input from precipitation, $Q_{c o n}$ the heat flux from the lower layer, $Q_{s}$ the sensible heat flux, and $Q_{l e}$ the latent heat flux. The units of the above parameters are $\left(\mathrm{J} / \mathrm{m}^{2}\right)$.

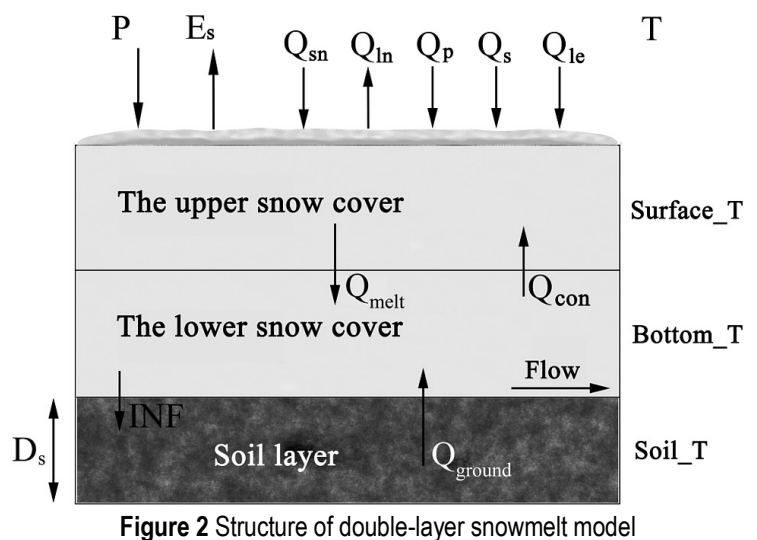

The energy balance of the lower snow layer can be calculated as

$\Delta Q=Q_{\text {ground }}-Q_{\text {con }}$,

where $\Delta Q$ is the net energy flux going into the lower layer per unit time, $Q_{c o n}$ the heat flux from the upper layer $\left(\mathrm{J} / \mathrm{m}^{2}\right)$, and $Q_{\text {ground }}$ the heat flux from the soil layer $\left(\mathrm{J} / \mathrm{m}^{2}\right)$.

The water balances of the two layers are calculated as

$W_{-}$Surface $=P-E-$ Surface_flow

$W_{-}$Bottom $=$Surface_flow $-I N F-$ Bottom_flow

where $W$ Surface is the variation of snowmelt water in the upper layer, $W_{-}$Bottom the variation of snowmelt water in the lower layer, $E$ the evaporation of the snow, Surface_flow the water infiltration of the upper snow layer into the lower layer after melting, $P$ the water input through precipitation, INF the infiltration into the soil layer, and Bottom flow the outflow of the lower snow layer.

The energy balance of the single-layer snow cover is calculated as

$Q_{\text {net }}=Q_{s n}+Q_{\mathrm{ln}}+Q_{p}+Q_{s}+Q_{\text {le }}+Q_{\text {ground }}$

where the meaning of each term is the same as in (1) and (2).

\subsubsection{Net Radiation on Snow Surface}

The net short-wave radiation flux $Q_{s n}$ in WRF is mainly controlled by the factor of albedo:

$Q_{s n}=\left(1-A_{s f c}\right) \cdot Q_{s}$

where $A_{s f c}$ is the surface albedo and $Q_{s}$ the shortwave radiation received by the surface. When the snow depth is more than $0.1 \mathrm{~m}$, the snow layer will completely block the solar radiation and $A_{s f c}$ is equal to the snow albedo $\left(A_{s}\right)$; however, when the snow depth is less than $0.1 \mathrm{~m}$, the snow layer will be transmitted through the sunlight, and the snow cover and the soil will both have an impact on the surface albedo. Consequently: $A_{s f c}=r A_{b g}+(1-r) A_{s}$, where $A_{b g}$ is the albedo of bare land. 
The snow age, solar radiation, and average daily temperature all have direct impacts on the snow-layer albedo. Kendo [18] proposed an exponential equation based on snow age, where $\alpha(0)$ is the albedo of the snow layer and $\alpha_{\min }$ is its minimum albedo. Winther [19] proposed the equation $A_{s}=0.90-0.92 \times 10^{-4} T_{a c c}$ $0.0042 Q_{s}$ according to the solar radiation and cumulative daily temperature, in which $T_{a c c}$ is the maximum accumulated temperature in a snowfall day.

The $Q_{l n}$ is estimated through formula (7):

$Q_{\ln }=L \downarrow+L \uparrow=\left(1+a_{c} C^{2}\right) \sigma T_{a}^{4}-\varepsilon_{s} \sigma T_{s}^{4}$

where $L \uparrow$ is the outward long-wave radiation from the snow surface, $L \downarrow$ the incident long-wave radiation from the atmosphere, $T_{a}$ the air temperature $(\mathrm{K}), T_{s}$ the snow surface temperature $(\mathrm{K}), \varepsilon_{s}=0.95$ (the emissivity of the snow cover), $\sigma=5.67 \mathrm{~K}^{-4} \times 10^{-8} \mathrm{~W} \cdot \mathrm{m}^{-2}$ (the StefanBoltzmann constant), $a_{c}$ refers to the cloud-type empirical coefficient, and $C$ is in the range between 0 and 1 . The value of $a_{c}$ is as follows: stratus, $a_{c}=0.24$; stratocumulus, $a_{c}=0.22$; cumulus, $a_{c}=0.20$; altostratus, $a_{c}=0.20$; altocumulus, $a_{c}=0.17$; stratocirrus, $a_{c}=0.08$; cirrus, $a_{c}=$ $0.04)$.

\subsubsection{Heat Input from Precipitation}

$Q_{p}$ is estimated through formula (8):

$Q_{p}=\rho_{w} c_{w}\left(T_{a}-273.16\right) P_{r}+\rho_{w} c_{i}\left(T_{a}-273.16\right) P_{s}$

where $\rho_{w}$ is the density of the water $\left(\mathrm{kg} / \mathrm{m}^{3}\right), c_{w}$ the specific heat of the water $[\mathrm{J} /(\mathrm{kg} \cdot \mathrm{K})], c_{s}$ the specific heat of the ice $[\mathrm{J} /(\mathrm{kg} \cdot \mathrm{K})], T_{a}$ the air temperature $(\mathrm{K}), P_{s}$ the snow water equivalent, and $P_{r}$ the amount of rainfall.

The condition of the snow or rain is decided by the air temperature.

When $T_{a}<T_{s}, P=P_{s}$, and when $T_{a}>T_{r}, P=P_{r}$; $p_{r}=\frac{p\left(T_{a}-T_{s}\right)}{T_{r}-T_{a}}$, and $p_{s}=1-p_{r}$, where $T_{r}=276.15 \mathrm{~K}$ (the critical temperature of the rainfall) and $T_{s}=272.15 \mathrm{~K}$ (the critical temperature of the rainfall of snowfall).

\subsubsection{Sensible and Latent Heat Flux}

The latent heat flux refers to the heat transfer caused by evaporation and condensation, and the sensible heat flux refers to the heat conduction between the air and snow. The latent heat flux and sensible heat flux are calculated as follows [20,21]:

$$
\begin{aligned}
& Q_{\ln }=0.622 h_{v}\left[e\left(T_{s}\right)-e\left(T_{a}\right)\right] / R_{d} T_{a} r \\
& Q_{s}=\rho_{\text {air }} c_{g}\left(T_{a}-T_{s}\right) / r \\
& r=\frac{\ln \left(\frac{\mu+z_{m}}{z_{m}}\right) \cdot \ln \left(\frac{x+z_{h}}{z_{h}}\right)}{k^{2} \mu}
\end{aligned}
$$

where $h_{v}=2.834 \times 10^{6} \mathrm{~J} / \mathrm{kg}$ is the sublimation latent heat, $R_{d}=287 \mathrm{~J} \cdot \mathrm{kg}^{-1} / \mathrm{K}^{-1}$ the dry air constant, $e\left(T_{a}\right)$ and $e\left(T_{s}\right)$ the vapor pressure of the air and snow, respectively, $\rho_{\text {air }}=1.293 \mathrm{~kg} / \mathrm{m}^{3}$ the density of the air under standard atmospheric pressure, $c_{g}=1.0 \times 10^{3} \mathrm{~J}$ the atmospheric specific heat capacity, $r$ the aerodynamic resistance, $x$ the elevation of the data being obtained, wind is characterized by unpredictability and variability [22], $\mu$ the wind speed which is a time series data [23], and $z_{h}=0.0002$ and $z_{m}=0.001$ the dynamic resistance coefficient of heat and water vapor, respectively.

The latent heat of the surface snow is calculated as

$$
Q_{l e}=-\frac{h_{v} \cdot 0.622}{R_{d} \times\left(T_{a}+273.13\right) \times r_{a s}} \times\left[e\left(T_{a}\right)-e\left(T_{s}\right)\right]
$$

Here, the snow surface is regarded as saturated, and the vapor pressure of the snow surface can be regarded as the saturation vapor pressure. The vapor pressure of the air is a product of the saturation vapor pressure under the air temperature and relative humidity $(R H)$ :

$$
\begin{aligned}
& e\left(T_{s}\right)=e_{s v p(T s)} \\
& e\left(T_{a}\right)=e_{s v p(T a)} \times R H
\end{aligned}
$$

where $e_{s v p}$ is the saturation vapor pressure, which is a function of temperature and can be calculated by the Teten equation:

$e_{\text {svp }}=100 \times 6.112 \times e^{17.67 \times T_{a} /\left(T_{a}+243.50\right)}$

\subsubsection{Heat Flux from Lower Layer}

In this study, the temperature gradient is used to calculate the heat transfer between snow covers:

$Q_{\text {con }}=q \times S$

where $q=-k_{\text {eff }}(\mathrm{d} t / \mathrm{d} z)$ is the heat flux density of the snow $\left(\mathrm{W} \cdot \mathrm{m}^{-2}\right), s$ the area of the snow cover grid, and $k_{\text {eff }}$ is the coefficient of the snow's heat conduction.

When the relative density of the snow layer is less than $0.156, k_{\text {eff }}=0.138-1.101 \rho+3.233 \rho^{2} ;$ otherwise, $k_{\text {eff }}=0.023 \rho+0.234 \rho^{2}$. The temperature gradient of the snow cover $\left(\mathrm{K} \cdot \mathrm{m}^{-1}\right)$ is $(\mathrm{d} t / \mathrm{d} z)=($ bottom_T surface $T) / \Delta h$, where $\Delta h$ is the difference in elevation between the snow layers.

\subsubsection{Heat Flux from Soil Layer}

Compared to the solar radiation, latent heat, and sensible heat, the heat flux from the soil layer can be regarded as having less impact on the process of snow melting. Its value is generally between 0 and $10 \mathrm{~W} \cdot \mathrm{m}^{-2}$ [24]. In this study, the relationship between the soil layer and snow layer used is as shown in the following equation $[25]$ : 
$Q_{\text {ground }}=k_{g} d T_{g} / d_{z}=k_{g}\left(T_{g}-T_{s}\right) /\left(z_{2}-z_{1}\right)=k_{g}\left(T_{g}-T_{s}\right) / z_{2}$

where $\mathrm{d} T_{g} / \mathrm{d} z$ is the temperature gradient of the soil layer, $k_{g}$ the coefficient of the soil layer's heat conduction, $T_{s}$ the temperature of the under-layer snow, and $T_{g}$ the temperature of the under-layer soil (with a depth of $z_{2}$ ).

\subsection{Calculation Flow of Snow Melting}

Under the condition of double-layer snow, the melting of the surface layer can affect both the lower layer and the entire snow cover.

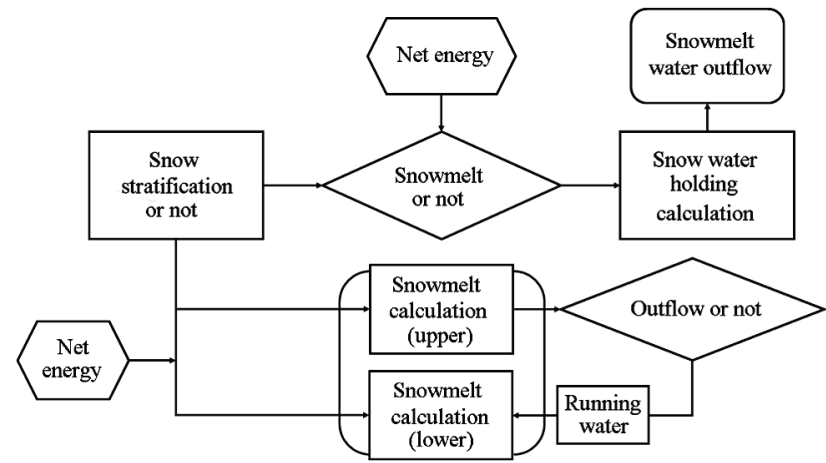

Figure 3 Calculation flowchart of the snow-melting process

Therefore, the snow-melting process of the upper layer is estimated first, during which there is only infiltration without the lateral flow of the snowmelt water. The snow-melting process of the lower layer is then estimated. Finally, the total outflow amount of the two layers is identified as that of the entire snow cover. The process is shown in Fig. 3.

\subsubsection{Infiltration into Soil Layer}

The melting of the frozen soil generally occurs later than the melting of the snow. During the melting of the frozen soil, the infiltration of the snowmelt water is minor, with excess infiltration as the main pattern. As the air temperature rises and the melting layer of the frozen soil thickens, in addition to the rate of the snow-melting increasing, the snow-melting infiltration also increases and the runoff becomes a combination of excess storage and excess infiltration. The equation for the relationship between the snow and the frozen soil is represented by [25]:

$$
I N F=C S_{0}^{2.92}\left(1-S_{1}\right) \cdot 1.64 \cdot\left[\left(273.15-T_{\text {soil }}\right) / 273.15\right]^{-0.45} \cdot t^{0.44}(18)
$$

where $S_{0}$ is the moisture of the soil layer $\left(\mathrm{m}^{3} / \mathrm{m}^{3}\right), S_{1}$ the initial moisture of the soil layer $\left(\mathrm{m}^{3} / \mathrm{m}^{3}\right), C=1.1$ the infiltration coefficient, $T_{\text {soil }}$ the temperature of the soil layer $(\mathrm{K})$, and $t$ the time interval (h).

\subsubsection{Calculation of Confluence}

The confluence process is calculated as a gridded form and is divided into slopes and rivers along the path. The river network is extracted using the digital elevation model (DEM) of the study area, and the slopes and rivers are determined by the threshold of the catchment grid with a field investigation having been carried out to validate the data [26]. The corresponding time interval of the confluence is then calculated. The river grid is numbered, and the flow direction matrix is employed to calculate the confluence path and traverse the confluence grids, so the confluence time can be estimated.

\subsection{Input Data \\ 3.4.1 DEM data}

The DEM data collected by this study are the $30 \mathrm{M}$ resolution data processed by the Advanced Spaceborne Thermal Emission and Reflection Radiometer Global Digital Elevation Map (ASTER GDEM) version 1 (V1) data. Pretreatment is carried out to reduce the error of flow directions in flat areas and the error of no outflow in low-lying lands. According to the actual situation in the study area, the superposition of the height increment is used to calculate and fill the low-lying lands to reduce their impact. ArcGIS (Esri, Redlands, CA, USA) is used to analyze the pretreated DEM data relating to the flow directions, confluence accumulation, river networks, and sub-river basins [27].

\subsubsection{Land-Use Data}

Land uses can change the drainage conditions of watersheds [28]. In this study, the land-use and land-cover change (LUCC) data used are the land-cover products over China $\left(250 \times 250 \mathrm{~m}^{2}\right.$ resolution $)$ provided by the Cold and Arid Regions Science Data Center at Lanzhou.

\subsubsection{Meteorological Data}

The WRF weather forecast data used in this study is derived from the China Meteorological Assimilation Driving Dataset (CMADS) official website (http://www.cmads.org/nr.jsp) [29], Since the latest version of the data source has only been updated through 2010 , the simulation and validation period of this study extends through 2010 only (2010 included); the 2016 datasets will be updated soon.

\subsubsection{Soil Data}

The Harmonized World Soil Database (HWSD) is resampled by ArcGIS and is interpolated into a spatial resolution of $30 \mathrm{~m}$, which meets the models' accuracy requirements [30].

\subsubsection{Snow Feature Extraction}

The model requires corresponding snow information, including the snow area, snow depth, and snow density, among which the data relating to the first two are interpreted and retrieved by MODIS, while the snow density is measured by field observation.

\subsection{Snow Area}

The snow cover index method and the images from the fourth and sixth bands of MODIS are used to calculate the 
normalized difference snow index; the equation is as shown in the following equation [24]:

$N D S I=\left(R_{4}-R_{6}\right) /\left(R_{4}+R_{6}\right)$

where $R_{4}$ and $R_{6}$ are the albedos of the fourth and sixth bands, respectively.

\subsection{Snow Depth}

The snow depth is retrieved through the relationship between the snow depth and impact factors, as shown by Li's equation [31]:

$S D=A_{1} X_{1}+A_{2} X_{2}+A_{3} X_{3}+\ldots A_{n} X_{n}+A_{n}+1$

where $S D$ is the snow depth; $X_{1}, X_{2}, \ldots, X_{n}$ are the impact factors; and $A_{1}, A_{2}, \ldots, A_{n}$ are the regression coefficients.

The study area is covered by grass and a small amount of forest; a model that combines the above relationship has been derived as follows:

For the grassland,

$S D=3.739822 X_{1}+2.949741 X_{2}+3.609386 X_{3}-50.333(21)$

For the forest,

$S D=3.076262 X_{1}+2.315176 X_{2}+1.987706 X_{3}-31.328$

\section{RESULTS AND DISCUSSION \\ 4.1 Comparison of Numerical Forecasts}

The WRF data are compared to the CMA/NMC T639L60 (http://www.weather.gov.cn/publish/nwp/t639/n -h/mslp.html) simulated data and the observational data from weather stations. The main parameters involved are the solar shortwave radiation, air temperature, soil moisture, soil temperature, relative humidity, and precipitation.

The error of the data is verified by the root-meansquare error (RMSE), mean absolute error (MAE), extreme value, mean, and regression analysis. The RMSE and MAE are calculated as follows:

$$
\begin{aligned}
& R M S D=\frac{1}{n} \sqrt{\sum_{i=1}^{n}\left(x_{\mathrm{sim}(i)}-x_{o b s(i)}\right)^{2}} \\
& M A E=\frac{1}{N} \sum_{i=1}^{N}\left|x_{o b s(i)}-x_{\operatorname{sim}(i)}\right|
\end{aligned}
$$

\subsection{Comparison of Shortwave Radiation}

In order to analyze the scientific quality of the results and consistency of the data, the data recorded during the period 01:00-12:00 AM every day between March 1 and 30, 2010 was selected to compare the shortwave radiation. A comparison of the shortwave radiation obtained from the WRF simulated values and the observed values are shown in Fig. 4.

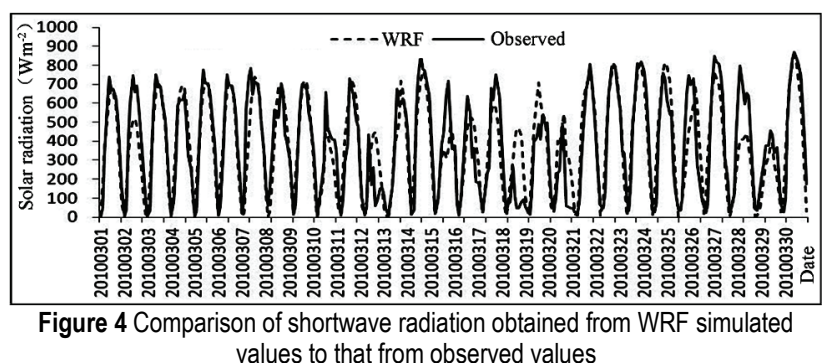

It can be seen from Fig. 4 that the WRF simulated value was higher on March 18 and 19, which was mainly due to the snowfall in the experimental area. In the simulation period, the resolution of the elevation data used in the WRF was $1000 \mathrm{~m}$, which can also generate corresponding errors.

Table 1 Statistical analysis of WRF simulated values and observed values of shortwave radiation

\begin{tabular}{|c|c|c|c|c|c|c|}
\hline & \multicolumn{4}{|c|}{ Radiation $\left(\mathrm{W} \cdot \mathrm{m}^{-2}\right)$} & MAE & RMSD \\
\cline { 1 - 5 } & Min & Max & Total & Mean & $\mathrm{W} \cdot \mathrm{m}^{-2}$ & $\mathrm{~W} \cdot \mathrm{m}^{-2}$ \\
\hline Obs & 4.145 & 871.0 & 127600.2 & 386.6 & \multirow{2}{*}{93.2} & \multirow{2}{*}{6.9} \\
\hline WRF & 0 & 850.7 & 124394.3 & 376.9 & & \\
\hline
\end{tabular}

It can be seen from Tab. 1 that the differences between the WRF and observation values regarding the means and extreme values are within $50 \mathrm{~W} \cdot \mathrm{m}^{-2}$, the MAE is within $95 \mathrm{~W} \cdot \mathrm{m}^{-2}$, and the overall error of shortwave radiation is $2.512 \%$.

A regression analysis of the observed values and WRF simulated values is conducted using Statistical analysis System (SAS) software (Tab. 2), resulting in a linear equation of $y=0.95491 x+26.71162$. The correlation between the equation and the variables was verified by the $F$ test with a confidence level of 0.0001 , which shows that the snowmelt model can meet the required level of prediction accuracy.

Table 2 Regression results of WRF-simulated values and observed values of shortwave radiation

\begin{tabular}{|c|c|c|}
\hline & Intercept & WRF \\
\hline Parameter & 26.71162 & 0.95491 \\
\hline Standard Error & 12.92921 & 0.02891 \\
\hline$t$-Value & 2.07 & 33.03 \\
\hline$P_{r}>|t|$ & 0.0396 & $<0.0001$ \\
\hline$F$-Value & \multicolumn{2}{|c|}{$<0.0001$} \\
\hline$P_{r}>F$ & \multicolumn{2}{|c|}{0.7688} \\
\hline$R^{2}$ & \multicolumn{2}{|c}{} \\
\hline
\end{tabular}

\subsection{Comparison of Air Temperature}

The observed temperature $2 \mathrm{~m}$ above the ground in the experimental field was compared with the variable $T_{2}$ in the WRF. The results show that the systematic error of the WRF is approximately $3{ }^{\circ} \mathrm{C}$. The corrected simulated values of the WRF and the observed values are shown in Fig. 5.

It can be seen from Tab. 3 that the accumulated error of simulation is $394.095^{\circ} \mathrm{C}$, and the mean error is about $0.5^{\circ} \mathrm{C}$. The simulated value of the MAE is $3.471{ }^{\circ} \mathrm{C}$, the corrected value is $1.334^{\circ} \mathrm{C}$, and the average correction is $0.456{ }^{\circ} \mathrm{C}$. These results show that the difference between the corrected simulated data and the observed data is not large. 


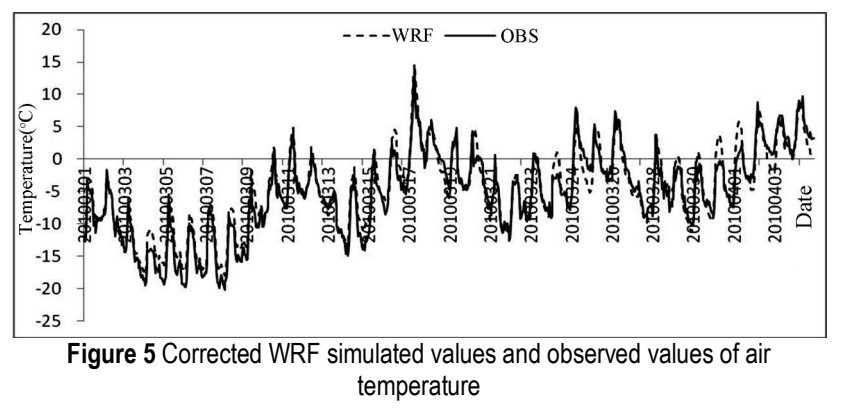

Table 3 Statistical analysis of WRF simulated values, corrected values, and observed values of air temperature

\begin{tabular}{|c|c|c|c|}
\hline $\begin{array}{c}\text { Temperature } \\
\left({ }^{\circ} \mathrm{C}\right)\end{array}$ & Observed & Simulated & Corrected \\
\hline Minimum & -20.170 & -15.013 & -18.013 \\
\hline Maximum & 13.787 & 17.779 & 14.779 \\
\hline Accumulation & -4543.104 & -1557.009 & -4149.009 \\
\hline Mean & -5.258 & -1.802 & -4.802 \\
\hline $\begin{array}{c}\text { Accumulated } \\
\text { Error }\end{array}$ & $/$ & 2986.095 & 394.095 \\
\hline ME & $/$ & 3.456 & 0.456 \\
\hline MAE & $/$ & 3.471 & 1.334 \\
\hline
\end{tabular}

A regression analysis of the observed values and the WRF simulated values is conducted using SAS software (Tab. 4), resulting in a linear equation, $y=0.95491 x+26.71162$. The goodness of fit, $R^{2}$, was 0.9409 and the correlation between the equation and the variables was verified by the $F$ test with a confidence level of 0.0001 .

Table 4 Regression analysis of WRF-simulated values and observed values of air temperature

\begin{tabular}{|l|c|c|}
\hline & Intercept & WRF \\
\hline Parameter & -0.30199 & 1.03210 \\
\hline Standard Error & 0.06858 & 0.00881 \\
\hline$t$-Value & -4.40 & 117.12 \\
\hline$P_{r}>|t|$ & $<0.0001$ & $<0.0001$ \\
\hline$F$-value & \multicolumn{2}{|c|}{13717.2} \\
\hline$P_{r}>F$ & $<0.0001$ \\
\hline$R^{2}$ & \multicolumn{2}{|c|}{0.9409} \\
\hline
\end{tabular}

\subsection{Comparison of Relative Humidity}

The relative humidity of air contributes greatly to the evapotranspiration of the snow-melting process. A comparison of the relative humidity obtained from the WRF simulated values and the observed values are shown in Fig. 6.

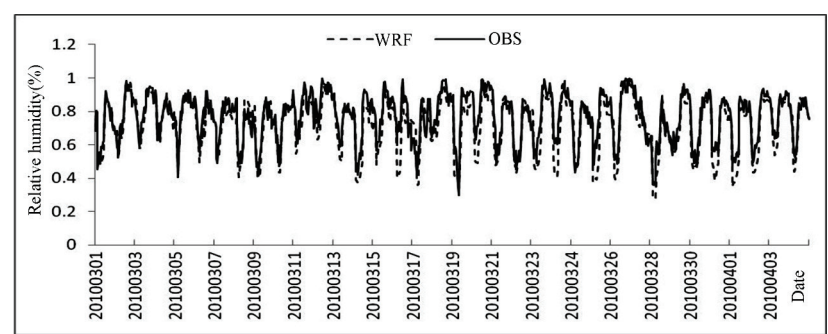

Figure 6 WRF simulated values and observed values of relative humidity

It can be seen from Tab. 5 that the maximum error is small, the mean error is $2.3 \%$, and the RMSE is $0.27 \%$.

A regression analysis of the observed values and the WRF simulated values is conducted using SAS software
(Tab. 6), resulting in a linear equation, $y=0.79963 x+0.1834$, with a goodness of fit, $R^{2}$, of 0.8134 , which meets the required accuracy.

Table 5 A statistical analysis of the WRF-simulated values and observed values of the relative humidity

\begin{tabular}{|c|c|c|c|c|c|}
\hline & \multicolumn{3}{|c|}{ Relative Humidity (\%) } & \multirow{2}{*}{$\begin{array}{c}\text { MAE } \\
(\%)\end{array}$} & \multirow{2}{*}{$\begin{array}{c}\text { RMSD } \\
(\%)\end{array}$} \\
\hline & Min & Max & Mean & & \\
\hline Obs & 29.55 & 99.69 & 76.476 & \multirow{2}{*}{6.154} & \multirow{2}{*}{0.2676} \\
\hline WRF & 27.84 & 99.81 & 74.743 & & \\
\hline
\end{tabular}

Table 6 A regression analysis of the WRF-simulated values and observed

\begin{tabular}{|l|c|c|}
\multicolumn{2}{l}{} & values of the relative humidity \\
\hline Parameter & Intercept & WRF \\
\hline Standard Error & 0.18340 & 0.95491 \\
\hline$t$-Value & 0.00971 & 0.02891 \\
\hline$P_{r}>|t|$ & 18.89 & 33.03 \\
\hline$F$-Value & $<0.0001$ & $<0.0001$ \\
\hline$P_{r}>F$ & \multicolumn{2}{|c|}{3762.63} \\
\hline$R^{2}$ & $<0.0001$ \\
\hline
\end{tabular}

\subsection{Comparison of Soil Temperature}

The soil temperature also contributes greatly to the speed of the snow-melting process. A comparison of the soil temperature obtained from the WRF simulated values and observed values are shown in Fig. 7.

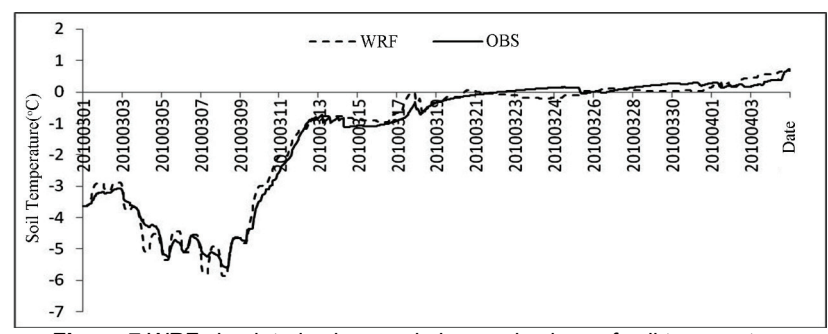

Figure 7 WRF simulated values and observed values of soil temperature

It can be seen from Tab. 7 that the maximum error is within $0.3{ }^{\circ} \mathrm{C}$, the MAE is $0.18 \%$, and the RMSE can be regarded as zero.

Table 7 A statistical analysis of the WRF-simulated values and observed values of the soil temperature

\begin{tabular}{|c|c|c|c|c|c|}
\hline & \multicolumn{3}{|c|}{ Soil temperature $\left({ }^{\circ} \mathrm{C}\right)$} & \multirow{2}{*}{$\begin{array}{c}\text { MAE } \\
\left({ }^{\circ} \mathrm{C}\right)\end{array}$} & \multirow{2}{*}{$\begin{array}{c}\text { RMSD } \\
\left({ }^{\circ} \mathrm{C}\right)\end{array}$} \\
\hline & Min & Max & Mean & & \\
\hline Obs & -5.86 & 0.669 & -1.3182 & \multirow{2}{*}{0.1826} & \multirow{2}{*}{0.00788} \\
\hline WRF & -5.60 & 0.719 & -1.3365 & & \\
\hline
\end{tabular}

Table 8 Regression analysis of WRF-simulated values and observed values of

\begin{tabular}{|l|c|c|}
\hline & Intercept & WRF \\
\hline Parameter & -0.02917 & 0.99147 \\
\hline Standard Error & 0.00953 & 0.00412 \\
\hline$t$-Value & -0.306 & 240.52 \\
\hline$P_{r}>|t|$ & 0.0023 & $<.0001$ \\
\hline$F$-Value & \multicolumn{2}{|c|}{57849.5} \\
\hline$P_{r}>F$ & \multicolumn{2}{|c|}{$<0.0001$} \\
\hline$R^{2}$ & \multicolumn{2}{|c|}{0.9853} \\
\hline
\end{tabular}

A regression analysis of the observed values and the WRF simulated values was conducted (Tab. 8), resulting in a linear equation, $y=0.99147 x-0.02917$, with a 
goodness of fit, $R^{2}$, of 0.9853 , which meets the required accuracy.

\subsection{Comparison of Soil Moisture}

It can be seen from Fig. 8 that the observed values were not significantly different from the WRF simulated values before the melting of seasonal frozen soils. The observed values are higher than the simulated values after March 24, which can be interpreted as the impact of snowmelt water infiltration on the soil moisture due to the warming process. Because of the large diurnal temperature difference, the snowmelt water infiltration in the day increases the soil moisture, while the freezing of the water at night decreases it. This is why there are diurnal fluctuations in the curve. After March 27, the trend became gentler due to the decreasing temperature and less snow melting. After that, the soil moisture continues to increase and the diurnal fluctuations appear again. A comparison of the soil moisture obtained from the WRF simulated values and the observed values are shown in Fig. 8.

It can be seen from Tab. 9 that the maximum error is within 0.1 , the mean error is 0.05 , the minimum error is within 0.07 , and the RMSE is $6.5 \%$.

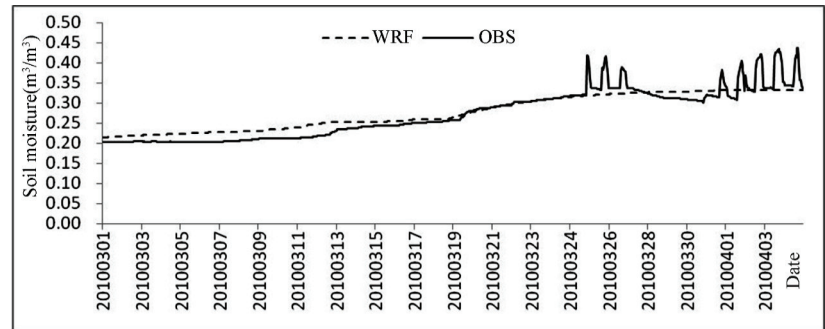

Figure 8 WRF simulated values and observed values of soil moisture

Table 9 Statistical analysis of WRF simulated values and observed values of soil moisture.

\begin{tabular}{|c|c|c|c|c|}
\hline & \multicolumn{3}{|c|}{ Soil moisture $\left(\mathrm{m}^{3} / \mathrm{m}^{3}\right)$} & \multirow{2}{*}{ RMSE } \\
\cline { 1 - 3 } & Min & Max & Mean & \\
\hline Obs & 0.202 & 0.436 & 0.273 & \multirow{2}{*}{$6.5 \%$} \\
\hline WRF & 0.215 & 0.332 & 0.278 & \\
\hline
\end{tabular}

A regression analysis of the observed values and the WRF simulated values was conducted (Tab. 10), resulting in a linear equation, $y=1.31938 x-0.09339$, with a goodness of fit, $R^{2}$, of 0.8853 , which meets the required accuracy.

Table 10 Regression analysis of WRF simulated values and observed values of soil moisture

\begin{tabular}{|l|c|c|}
\hline & Intercept & WRF \\
\hline Parameter & -0.09339 & 1.31938 \\
\hline Standard Error & 0.00454 & 0.01616 \\
\hline$t$-Value & -20.59 & 81.65 \\
\hline$P_{r}>|t|$ & $<.0001$ & $<.0001$ \\
\hline$F$-Value & \multicolumn{2}{|c|}{6666.23} \\
\hline$P_{r}>F$ & \multicolumn{2}{|c|}{$<0.0001$} \\
\hline$R^{2}$ & \multicolumn{2}{|c|}{0.8853} \\
\hline
\end{tabular}

\subsection{Analysis of Runoff Model}

This study not only verifies the accuracy of the outflow in the watershed, but also compares the variation of the snow water equivalent in the study area with the corresponding MODIS remote sensing data.
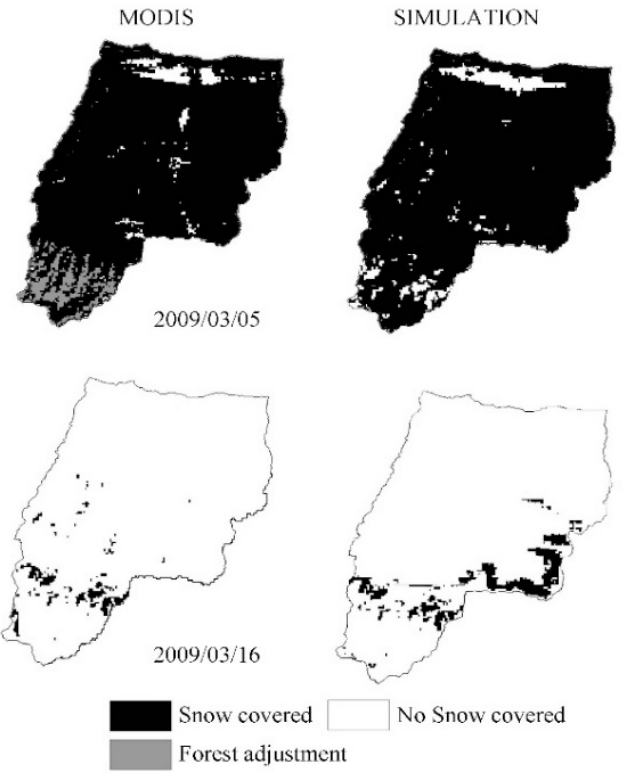

Figure 9 Spatial distributions of snow water equivalent in study area from MODIS data and simulation in 2009

\subsubsection{Spatial Distribution of Simulated Snowmelt}

The snow water equivalent of typical snow-melting periods in 2009 and 2010 was simulated and validated.

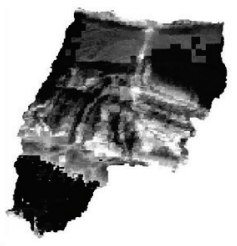

$2010 / 03 / 10$
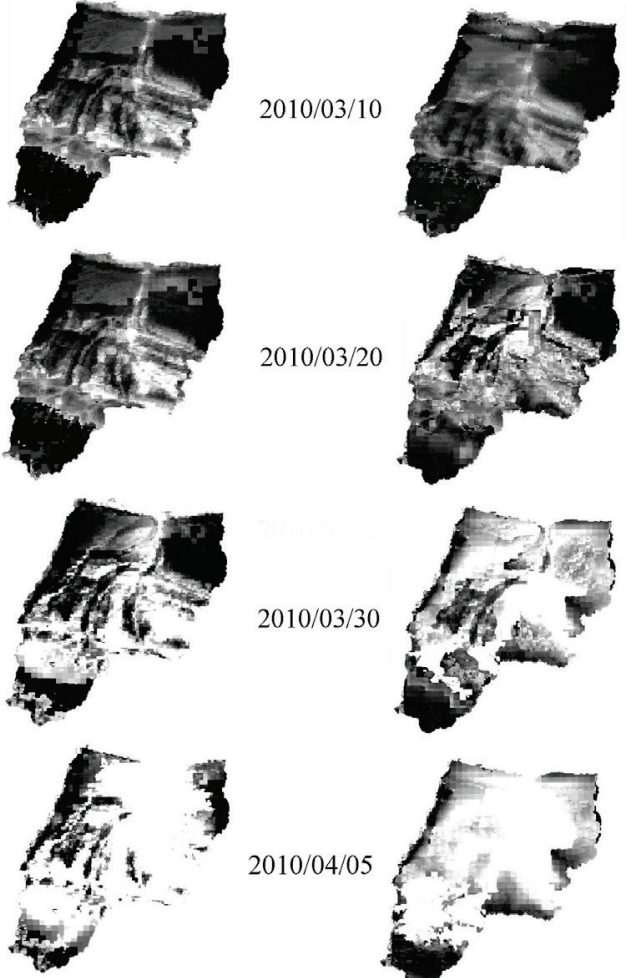

$2010 / 04 / 05$

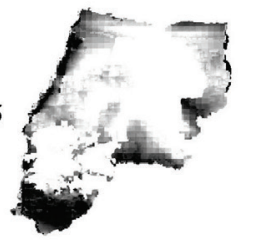

Snow water equivalent $(\mathrm{mm})$

$0-100$

Figure 10 Spatial distributions of snow water equivalent in study area from MODIS data and simulation in 2010

The validation was conducted using the mean observed snow density at the same time period. The simulation and MODIS data of the snow water equivalent 
for 2009 and 2010 are shown in Figs. 9 and 10, respectively.

\subsubsection{Simulation of Snowmelt Runoff}

The snow-melting process of this model is in an hourly resolution, which increases the difficulty of observation. Therefore, the observed data during the flood peak is used in the experiment, and the observed data during other periods is averaged. Comparisons of the snowmelt runoff obtained by the simulated and observed values for 2009 and 2010 are shown in Figs. 11 and 12, respectively.

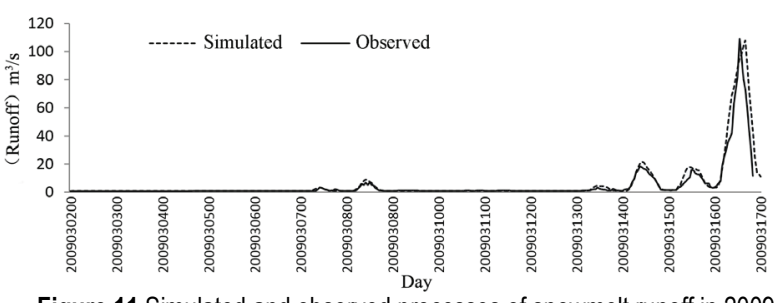

Figure 11 Simulated and observed processes of snowmelt runoff in 2009

It can be observed from Figs. 11 and 12 that the simulated snowmelt runoff process line corresponds well with that of the observation data. Figs. 13 and 14 show that the qualification ratios (QRs) of the forecasted snowmelt runoff in 2009 and 2010 were $87 \%$ and 90.85 $\%$, respectively, and the distortion ratio is less than $20 \%$ for the daily snowmelt runoff simulation.

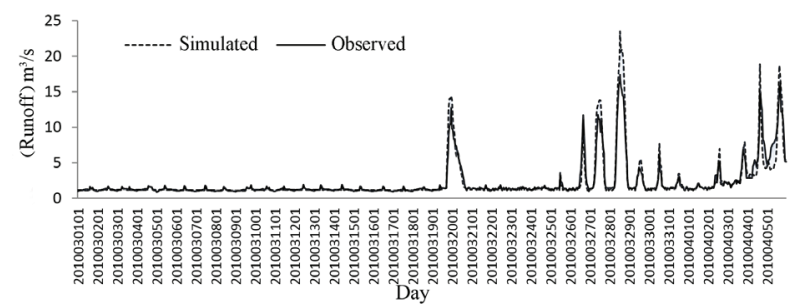

Figure 12 Simulated and observed processes of snowmelt runoff in 2010

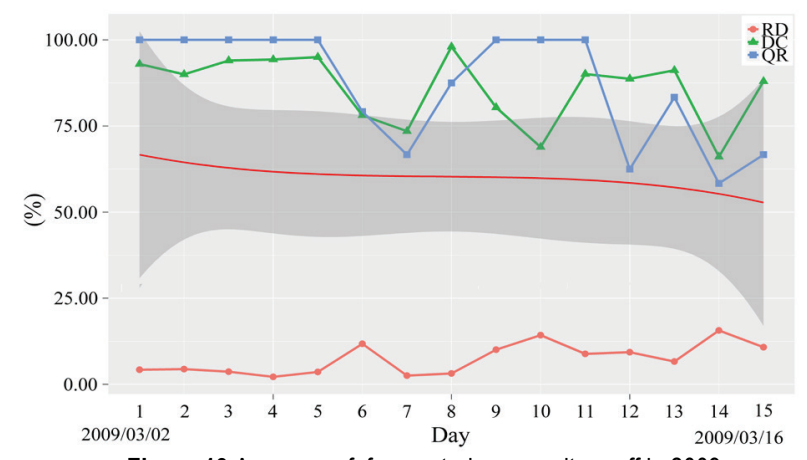

Figure 13 Accuracy of forecasted snowmelt runoff in 2009

The coefficients of determination of the model are 0.85 and 0.82 for 2009 and 2010, respectively, showing that the model's accuracy is high. According to the requirements of the "Standard for Hydrological Information and Hydrological Forecasting (SL2502000)", the accuracy of the model has reached Tier 2. However, due to the influence of the ablation of frozen soils, the forecasted flood peak is overestimated. This problem will be solved by an improvement to the modeled frozen soil layers.

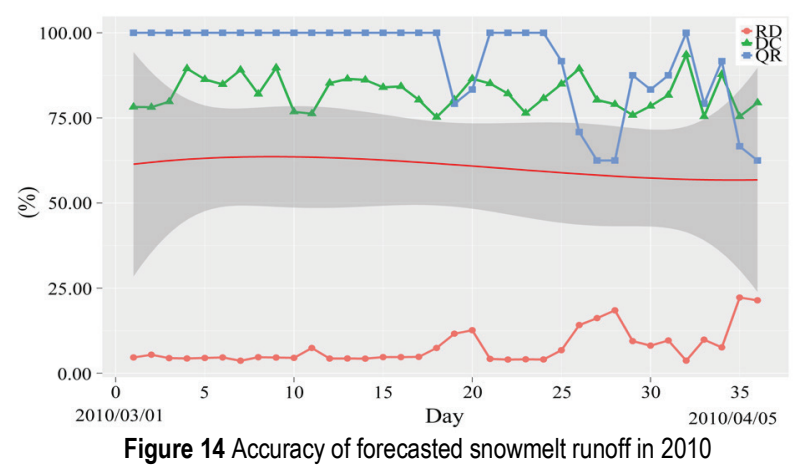

\section{CONCLUSIONS}

In order to predict the snowmelt flood in the northern slope of the Tianshan Mountains in Spring, a two-layer distributed snowmelt runoff model (TSRM) has been established based on the energy and mass balance for the Juntanghu Watershed on the north slope of the Tianshan Mountains. A simulation was conducted by coupling WRF with the TSRM. The conclusions of this study are as follows:

(1) The WRF-TSRM mode can provide an effective forecast and early warning for the snowmelt flood runoff on the north slope of the Tianshan Mountains. However, the WRF can only provide data with a resolution of $1 \times 1$ $\mathrm{km}^{2}$, which is larger than the hydrological unit on the grid scale. The data-matching problem could be the key to improving the simulation.

(2) During verification, it was found the simulation tends to overestimate the runoff during the later period of the flood peak. This is because the ablation state of the frozen soil layer below the snow layer is different. It is recommended that the role of the ablation of the frozen soil in the runoff become an important area for future research. In the future, more modules regarding the mechanisms of the frozen soil freeze-thaw process will be embedded in the two-layer distributed snowmelt runoff model.

(3) The impact of snowcover and seasonal frozen soil is also important. The threshold of the water-conservation capacity of snow cover changes with snow layer structure, and the infiltration capacity of the snowmelt also changes significantly due to the influence of the seasonal frozen soil, both of which will increase the uncertainty of the forecast. Therefore, it will be necessary to conduct an uncertainty analysis to further improve the model.

The WRF-TSRM mode proposed in this study fully combines the advantages of the atmosphere and land surface model, which provides important scientific and technological support for snowmelt flood forecasting in the northern slope of the Tianshan Mountains. However, due to the fact that WRF only covered 2010, we did not validate and improve the WRF-TSRM mode using more observational data. We will make more improvements after collecting more data.

\section{Acknowledgement}

This study was supported by Doctoral research foundation of Xinjiang University (BS150247), the China Postdoctoral Science Foundation (2017M610950), the 
National Scientific Foundation of China (NSFC) (41701076) and the National key Research and Development Program of China (2017YFC0404305).

\section{REFERENCES}

[1] Meng, X. Y., Yu, D. L. \& Liu, Z. H. (2015). Energy Balance-Based SWAT Model to Simulate the Mountain Snowmelt and Runoff-Taking the Application in Juntanghu Watershed (China) as an Example. Journal of Mountain Sciences, 12(2), 368-381. https://doi.org/10.1007/s11629-014-3081-6

[2] Meng, X. Y., Wang, H., Lei, X. H., Cai, S. \& Y.; Wu, H. J. (2017). Hydrological Modeling in the Manas River Basin Using Soil and Water Assessment Tool Driven by CMADS. Tehnicki Vjesnik-Technical Gazette, 24(2), 525-534.

[3] Wang, Y. J., Meng, X. Y. \& Liu, Z. H. (2016). Snowmelt Runoff Analysis under Generated Climate Change Scenarios for the Juntanghu River Basin in Xinjiang, China. Tecnología y Ciencias del Agua, 7(4), 41-54.

[4] Wang, J.; Li, W. J. Establishing simulated model of snowmelt runoff for large scale basin in Western China. // Journal of Glaciology and Geocryology, 21, 3(1999), 264268

[5] Wang, Z. G.; Liu, C. M. A review of the studies on distributed hydrological model based on DEM. // Journal of Natural Resources, 18, 2(2003), 168-173.

[6] Wang, S. G., Kang, E. S. \& Li, X. (2004). Progress and perspective of distributed hydrological models. Journal of Glaciology and Geocryology, 26(1), 61-65.

[7] Zhao, Q. D. \& Liu, Z. H. (2007). Improved snowmelt model based on EOS/MODIS remote sensing data. Arid Land Geography, 30(6), 915-920.

[8] Bao, A. M. \& Chen, X. (2010). Theories and methods of snowmelt runoff and its application in arid regions. Arid Land Geography, 33(5), 684-691.

[9] Yan, Y., Liu, Z. H. \& Ye, Z. X. (2010). Establishment and validation of early-warning model for snowmelt flood in North Xinjiang. Arid Land Geography, 32(4), 552-557.

[10] Pei, H. (2008). Design and Application of Distributed Snowmelt-Runoff Model. Resources Science, 30(3), 454459.

[11] Kennth, J., Westrick, F. \& Mass, C. (2001). An Evaluation of a High-Resolution Hydrometeorological Modeling System for Prediction of a Cool-Season Flood Event in a Coastal Mountainous Watershed. Journal of Hydrometeorology, 2(2), 161-180. https://doi.org/10.1175/15257541(2001)002<0161:AEOAHR>2.0.CO;2

[12] Evans, J. (2003). Improving the characteristics of streamflow modeled by regional climatemodels. Journal of Hydrology, 284(1-4), 211-227. https://doi.org/10.1016/j.jhydrol.2003.08.003

[13] Zhao, Q., Liu, Z., Ye, B., Qin, Y. \& Wei, Z. (2010). A snowmelt runoff forecasting model coupling WRF and DHSVM. Hydrology \& Earth System Sciences, 13(10), 1897-1906. https://doi.org/10.5194/hess-13-1897-2009

[14] Wu, X. J., Pan, X. D. \& Shen, Y. P. (2016). Validation of WRF model on simulationg forcing data for Kayiertesi River basin, Xinjiang. Journal of Glaciology and Geocryology, 38(2), 332-340.

[15] Feyen, J. (2001). Analysis of uncertainties associated with different methods to determine soil hydraulic properties and their propagation in the distributed hydrological MIKE SHE model. Hydrology, 246(1-4), 63-81. https://doi.org/10.1016/S0022-1694(01)00345-6

[16] Zhang, D., Zhang, W. C. \& Zhu, L. (2005). Improvement and application of SWAT-A physically based, distributed hydrological model. Scientia Geographica Sinica, 25(4), 434-441.

[17] Meng, X. Y., Wang, H., Wu, Y. P., Long, A. H., Wang, J. H., Shi, C. X. \& Ji, X. N. (2017). Investigating spatiotemporal changes of the land surface processes in Xinjiang using high-resolution CLM3.5 and CLDAS: Soil temperature. Scientific Reports, 7, 13268. https://doi.org/10.1038/s41598-017-10665-8

[18] Kondo, J. \& Yamazaki, T. (1990). A prediction model for snowmelt, snow surface temperature and freezing depth using a heat balance method. Journal of Applied Meteorology, 29(5), 375-384. https://doi.org/10.1175/15200450(1990)029<0375:APMFSS >2.0.CO;2

[19] Winther, J. (1993). Short and long-term variability of snow albedo. Nordic Hydrology, 24(1), 199-212.

[20] Gorchakova, I. A., Repina, I. A. \& Feigel'SonE, M. (1998). Cloud influence on radiative heat exchange in the atmosphere. Izvestiya Akademii Nauk Fizika Atmosfery $i$ Okeana, 34(1), 153-156.

[21] Yang, Y., Endreny, T. A. \& Nowak, D. J. (2011). iTree-Hydro: Snow Hydrology Update for the Urban Forest Hydrology Model. Jawra Journal of the American Water Resources Association, 47(6), 1211-1218. https://doi.org/10.1111/j.1752-1688.2011.00564.x

[22] Lepszy, S., Chmielniak, T. \& Monka, P. (2017). Storage system for electricity obtained from wind power plants using underground hydrogen reservoir. Journal of Power Technologies, 97(1), 61-68.

[23] Kumar, S. \& Lopez, D. (2015). Feature Selection used for Wind Speed Forecasting with Data Driven Approaches. Journal of Engineering Science and Technology Review, 8(5), 124-127.

[24] Cline, D. W. (1997). Snow surface energy exchanges and snowmelt at a continental, mid-latitude alpine site. Water Resources, 33(4), 689-701. https://doi.org/10.1029/97WR00026

[25] Abbott, M. B., Bathurst, J. C., Cunge, J. A., O' Connell, P. E. \& Rasmussen, J. (1986). An Introduction to the European Hydrological System-System Hydrological European "SHE" 2: Structure of a physically based distributed modeling system. Journal of Hydrological, 87(1), 61-77. https://doi.org/10.1016/0022-1694(86)90115-0

[26] Zhao, L. \& Gray, D. M. (1999). Estimating snowmelt infiltration into frozen soils. Hydrology Processes, 13(1), 1827-1842. https://doi.org/10.1002/(SICI)1099 1085(199909)13:12/13<1827::AID-HYP896>3.0.CO;2-D

[27] Hao, Z. C. \& Li, L. (2002). The method of creating of the net of river based 1on DEM. Journal of China Hydrology, 22(4), 8-10.

[28] Perea-Moreno, A., Aguilera-Ureña, M., Meroño-De Larriva, J. \& Manzano-Agugliaro, F. (2017). Using Digital Photogrammetry for Evaluating Soil Erosion Risk in Olive Ochards. DYNA, 92(1), 55-62.

[29] Meng, X. Y. \& Wang, H. (2017). Significance of the China Meteorological Assimilation Driving Datasets for the SWAT Model (CMADS) of East Asia. Water, 9(10), p. 765. https://doi.org/10.3390/w9100765

[30] Meng, X. Y., Ji, X. N. \& Liu, Z. H. (2013). Study on Snowmelt Runoff under Climate Change Effect in Tianshan Mountain in China. Nature Environment and Pollution Technology, 12(4), 555-562.

[31] Li, S. M., Fu, H. \& Huang, Z. (2006). Snow Depth Retrieval Using EOS/ MODIS. Arid Land Geography, 29(5), 719-725. 


\section{Contact information:}

Xianyong MENG, Ph.D.

State Key Laboratory of Simulation and Regulation of Water Cycle in River

Basin \& China Institute of Water Resources and Hydropower Research,

No. 1 Fuxing Road, Beijing, 100038, P. R. China

E-mail: mxy@iwhr.com

Zhiqun SUN, Ph.D. (Corresponding author)

College of Resource and Enviroment Sciences \& Xinjiang University,

Shengli Road, Urumqi, 830046, P. R. China

E-mail: szq1029@126.com

Honggang ZHAO, Ph.D. (Corresponding author)

College of Chemical Engineering, Xinjiang Normal University,

Xinyi Road, Urumqi, 830046, P. R. China

E-mail: xjwzhg@163.com

Xiaonan Jl, Ph.D.

State Key Laboratory of Desert and Oasis Ecology,

Xinjiang Institute of Ecology and Geography,

Urumqi, 830046, P. R. China

E-mail: jixiaonan999@163.com

Wang HAO, Ph.D., China Academy of Engineering (Corresponding author) State Key Laboratory of Simulation and Regulation of Water Cycle in River

Basin \& China Institute of Water Resources and Hydropower Research, Room A966, No.1 Fuxing Road, Beijing, 100038, P. R. China

E-mail: wanghao@iwhr.com

Lianqing XUE, Ph.D.

Hohai University, Gulou Road, Jiangsu, 210098, P. R. China

E-mail: lqxue@hhu.edu.cn

\section{Hongjing WU, Ph.D.}

NRPOP Lab, Faculty of Engineering and Applied Science, Memorial University of Newfoundland, St. John's, NL, T 709749 5201, Canada

E-mail: hjwu@mun.ca

\section{Yongnan ZHU, Ph.D.}

State Key Laboratory of Simulation and Regulation of Water Cycle in River Basin \& China Institute of Water Resources and Hydropower Research,

No. 1 Fuxing Road, Beijing, 100038, P. R. China

E-mail: zhyn@iwhr.com 